\title{
Treatment Experience of Total Atelectasis with Endotracheal Tube: Case Series
}

\author{
Ayse Sahin Tutak ${ }^{1 *}$, Huseyin Avni Findikli ${ }^{1}$, Ercan Cil ${ }^{2}$ \\ ${ }^{1}$ Department of Internal Medicine, Adiyaman University of Medical, Adiyaman, Turkey \\ ${ }^{2}$ Department of Chest Diseases, Adiyaman University of Medical, Adiyaman, Turkey
}

*Corresponding Author: Ayse Sahin Tutak, Department of Internal Medicine, Adiyaman University of Medical, Adiyaman, Turkey, Tel: +904162161015; E-mail: aysesahintutak@ hotmail.com

Received: 28 November 2018; Accepted: 10 December 2018; Published: 20 December 2018

\begin{abstract}
In cases where patient portable bronchoscopy is damaged or absance, a process that we think can be used endotracheal intubation method to treat total atelectasis . Total preliminary unprepared 10-15 minutes can be done with an experienced team. It is a process that can be carried out with mild sedation and patient is able to maintain saturation 90-95 with nasal oxygen after the procedure. In the absence of treatment of the patient with total or near total atelectasis, due to respiratory failure and aggravated pneumonia and mortality rates will increase. This article, when intensive care unit (ICU) bronchoscopy is impaired we performed three patients with right and left lung total atelectasis pre and post interventional procedure chest radiographs were evaluated.
\end{abstract}

Keywords: Atelectasis; Intensive care unit (ICU); Endotrachealtube (ETT)

\section{Introduction}

Atelectasis is a non-ventilated lung parenchyma. One of the most common causes of treatment bronchoscopy in patients Intensive care unit (ICU), cleaning of the main bronch inputs secondary to mucus plaques and coagulums [1]. In cases where tracheal aspirations are not sufficient bronchoscopy makes an important contribution [2]. Viscous mucus plaques and coagulums, obstruct the lobe and segment mouths. This patients with pulmonary reserve already not well. The most important reason of hypoxemia is the decrease in volume. The most common cause of atelectasis in critically ill patients, with abnormal chest x-ray, mucus plaques and accumulation of mostly bronchial secretions and develop due to decreased cough activity [3]. Bronchoscopy secretion for cleaning purposes have seen only $44 \%$ of patients achieved success [4]. 
We have in current low number of specialists in chest diseases, insufficient number of bronchoscopy or failure of timely maintenance, as a result of bronchoscopy can not be performed in atelectasis patients at any time. In this article, 3 patients with atelectasis who are intubated and extubated by endotrachealtube (ETT), who cannot be opened by deep tracheal aspiration and postural drainage are evaluated.

\section{Case Series}

\subsection{Case 1}

77 years old lady. The patient with right hemiparesis deformity, ICU was diagnosed with pneumonia. While under antibiotic therapy 4 days of hospitalization take a chest X-ray right total atelectasis detected patient. Since bronchoscopy was defective, the patien twas given a midazolom intravenous dose of $2 \mathrm{mg}$ and titrated the dose. After mild sedation is provided to the patient, her was intubated with ETT 7.5. ETT lip level was lowered to $22 \mathrm{~cm}$, then to $28 \mathrm{~cm}$ before the intervening procedure. Dry wet aspiration with $0.9 \% \mathrm{NaCl}$ was performed, while manual ventilation with ambu. The process was repeated 5-6 times in total. The procedure took 10 minutes and the patients oxygen saturation did not fall below 75. After the interventional process, chest x-ray (Figure 1) showed that the right main broncus was opened and patients were observed to monitor oxygen saturation at 90-95.
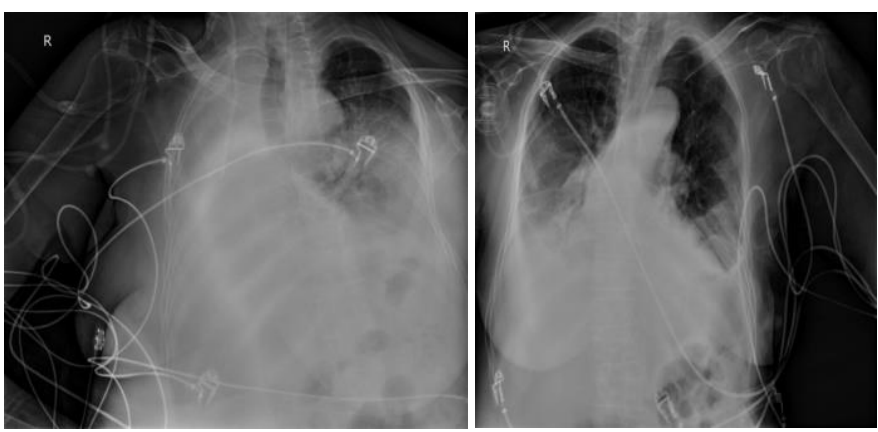

Figure 1: Case 1 lung graphs taken before and after the procedure.

\subsection{Case 2}

A 71-year-old female patient with Alzheimer's diagnosed respiratory distress was admitted to ICU admission. Chestradiography showed left total atelectasis. Because bronchoscopy was impaired, mild sedation was achieved with midazolom. He was intubated with ETT 7.5. While ETT lip level was $20 \mathrm{~cm}$, aspiration and ventilation with manuelambu were provided. Then the patient is turned to the left side and the lip level of the tube is lowered to 28 $\mathrm{cm}$. The procedure took 10-15 minutes and the patient's oxygen saturation did not fall below 75 . After the interventional process, chest x-ray (Figure 2) showed that the left main broncus was opened and patients were observed to monitor oxygen saturation at 90-95.

\subsection{Case 3}

84-year-old male patient with congestive heart failure and chronic renal failure, chest radiography revealed diffuse opacity in the left lung (atelectasis??). Since bronchoscopy was defective, the patient was given a midazolom 
intravenous dose of $2 \mathrm{mg}$ and titrated the dose. After mild sedation is provided to the patient, her was intubated with ETT 8. While ETT lip level was $22 \mathrm{~cm}$, aspiration and ventilation with manuel ambu were provided. Then the patient is turned to the left side and the lip level of the tube is lowered to $28 \mathrm{~cm}$. The procedure took 10-15 minutes and the patients oxygen saturation did not fall below 75-80. When the procedure ends without any complications. In the control lung x-ray there was a pleural effusion up to the middle zone starting from the basal. Seen upper and middle zone ventile parenchyma (Figure 3).
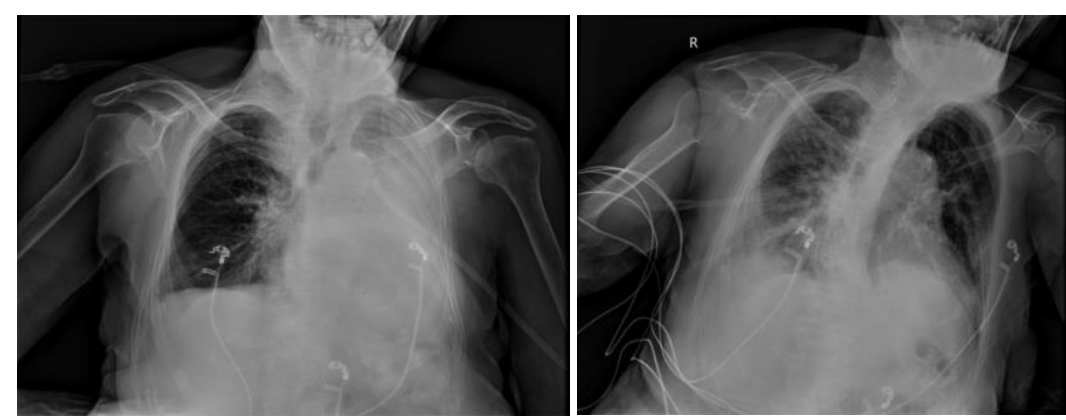

Figure 2: Case 2 lung graphs taken before and after the procedure.
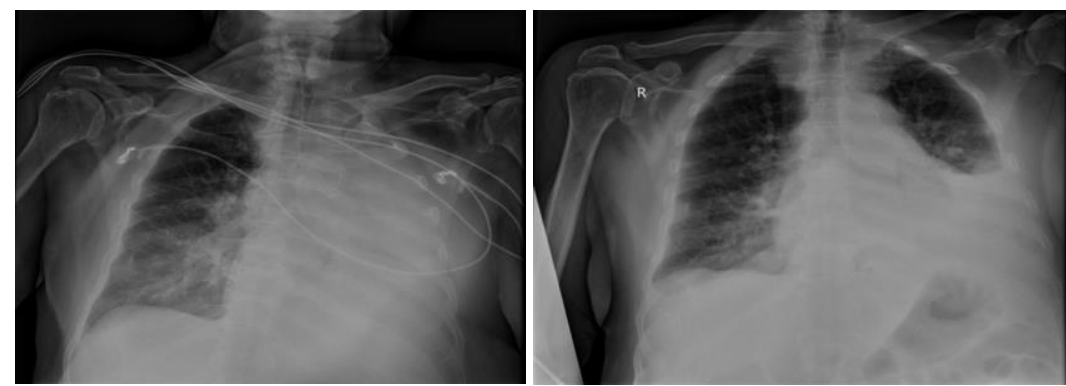

Figure 3: Case 3 lung graphs taken before and after the procedure.

\section{Discussion}

Internal Diseases ICU patients are mostly elderly patients with low muscle strength and chronic diseases. In this group of patients, atelectasis and associated infections are common. Bronchoscopy ICU can be used frequently for examination and treatment. With bronchoscopy, the doctor can see the surface of the bronchi, open the coagulom plugs, and take samples from the bronchial mucosa. Before the addition of humidification units to the mechanical ventilator system, routine $0.9 \% \mathrm{NaCl}$ is used in endotracheal aspiration applications in intensive care units [5]. The patient can be aspirated by with both dry aspiration and $0.9 \% \mathrm{NaCl}$. There are studies showing that the administration of $0.9 \% \mathrm{NaCl}$ salin aspiration in the literature is effective in the removal of secretions. There are contrasting views suggesting that this practice may lead to a reduction in arterial saturation and the transport of contaminated materials to deeper alveoli. In our cases, they were found to benefit from wet and dry aspiration through ETT. 
In our patients, atelectasis did not improve despite postural drainage and deep traceal aspiration, so bronchoscopy was planned. Bronchoscopy could not be completed becaused efective bronchoscopy. Patients could not be referred to another center because of poor condition. This interventional process was applied to the patient whose oksijen saturation started to decrease. Thanks to this interventional process, ETT was aspirated at the level of the maim bronch through the tube reaching the right or left main bronchus according to the position we had given to the patient after aspiration from the carina level. We think that atelectasis can be opened with compressed air by manuel ambu [6], it may be useful in those who do not benefit from aspiration. Aspiration procedure with ETT, It is an effective method for the removal of airway secretions in all patients related to the atelectasis.

In summary, frequently bronchoscopy ICU can be used for examination and treatment. To purpose aspirate the patient through ETT, can be used as an alternative method in atelectasis patients when we can not do bronchoscopy.

\section{References}

1. Marini JJ, Pierson DJ, Hudson LD. Acute lobar atelectasis: A prospective comparison of fiberoptic bronchoscopy and respiratory therapy. Am Rev Respir Dis 119 (1979): 971-978.

2. Jolliet P, Chevrolet JC. Bronchoscopy in theintensivecareunit. Intensive Care Med 18 (1992): 160-169.

3. Mahajan VK, Catron PW, Huber GL. The value of fiberoptic bronchoscopy in the management of pulmonary collapse. Chest 73 (1978): 817-820.

4. Kreider ME, Lipson DA. Bronchoscopy for atelectasis in the ICU: A case report and review of the literature. Chest 124 (2003): 344-350.

5. Akgul S, Akyolcu N. Effects of normal saline on endotracheal suctioning. J Clin Nurs 11 (2002): 826-830.

6. Levitan. PracticalAirway Management Course, Baltimore (2013).

7. Morrow BM, Futter MJ, Argent AC. Endotracheal suctioning: From principles to practice. Intensive Care Med 30 (2004): 1167-1174.

8. Ji YR, Kim HS, Park JH. Instillation of normal saline before suctioning in patients with pneumonia. Yonsei Med J 43 (2002): 607-612.

9. Freytag CC, Thies FL, Konig W, et al. Prolonged application of closed in-line suction catheters increases microbial colonization of the lower respiratory tract and bacterial growth on catheter surface. Infection 31 (2003): 31-37.

10. Raymond SJ. Normal saline instillation before suctioning: helpful or harmful? A review of the literature. Am J Crit Care 4 (1995): 267-271.

Citation: Ayse Sahin Tutak, Huseyin Avni Findikli, Ercan Cil. Treatment Experience of Total Atelectasis with Endotracheal Tube: Case Series. Archives of Internal Medicine Research 1 (2018): 015-019.

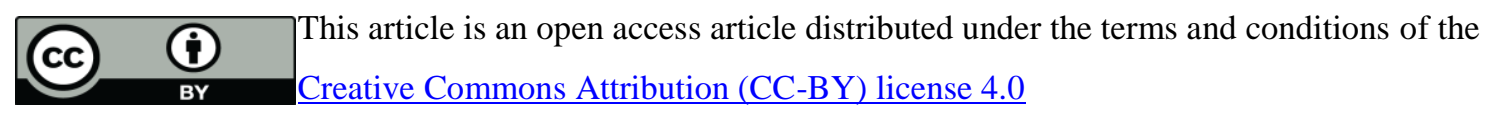

